\title{
Una nueva mirada sobre la historia económica y social. Su presentación en los libros de texto escolares de la última década ${ }^{1}$
}

Palmira Dobaño Fernandez-Mariana Lewkowicz-Román Mussi-Martha Rodriguez*

En general hay muy pocas investigaciones sobre libros de texto. Dentro de la escasa producción, los textos de nivel primario han suscitado mayor atención que los de escuela media. Respecto de los textos de historia en particular, en 1993 Ossana señalaba:

los trabajos e investigaciones sobre los textos de enseñanza de la historia en la escuela media no han recibido, hasta hace poco, atención alguna. ${ }^{2}$

Si bien es cierto que en los últimos años aparecieron algunas investigaciones todavía es poco lo que se los ha estudiado. ${ }^{3}$ Prácticamente no hay investigaciones sobre los textos producidos después de 1990, momento en el que comienzan importantes cambios. La falta de estudios es de subrayar, además, porque la mayoría de los textos escolares que se utilizan hoy fueron editados después de ese año.

Las directivas que dio la UNESCO en 1949 para promover los trabajos que evaluaran si las imágenes transmitidas por los textos escolares contribuían o no al entendimiento entre naciones, dieron algunos frutos pues surgen investigaciones sobre temas como el nacionalismo, la identidad nacional y la visión del "otro" en los textos escolares. Más recientemente el proceso de integración regional y los esfuerzos de cada país promovieron este tipo de estudios.

En el contexto de América Latina hay trabajos como los de Josefina Z. Vazquez y Peter Dressendörfer para los textos mejicanos, Nikita Harwich Vallenilla para el caso de Venezuela, entre otros. ${ }^{4}$ Con una perspectiva de este tipo se está desarrollando un proyecto conjunto entre Argentina y Chile, que se propone analizar la visión que transmite cada sistema escolar sobre el país vecino. El grupo argentino trabaja bajo la dirección de L. A. Romero. ${ }^{5}$

Para el caso específico de nuestro país, lo nacional y la nacionalidad fueron estudiados en los trabajos de Honoria Zelaya de Nader y María Suayter de Iñigo, ${ }^{6}$ que focalizan las imágenes sobre la inmigración en la primera mitad del siglo XX y de Fernando 
Devoto que trabaja la presentación de la inmigración y la "cuestión social". 7 Silvina Gvirtz vuelve sobre estos temas en su trabajo sobre las historias escolares argentinas y británicas, desde el punto de vista de las relaciones bilaterales. ${ }^{8}$ En 1993, Nikolaus Werz ${ }^{9}$ trabajó el modo en que aparecen en los textos las relaciones entre los países industrializados y las sociedades en desarrollo.

Todas las investigaciones señalan la existencia de un divorcio entre historiografía académica y libros de texto. La desactualización de éstos no es un fenómeno exclusivo de nuestro país sino un problema general, con características propias en cada caso. Berghahn y Schissler ${ }^{10}$ señalaron este desfasaje en los países de Europa Occidental y Norteamérica, donde la historia política y diplomática mantuvo su influencia en los colegios y libros de texto por lo menos hasta mediados de la década de 1960, aunque en los ámbitos académicos declinaba desde los años cuarenta.

En 1989 Silvia Finocchio realiza un estudio comparativo de los programas y textos de cuatro asignaturas en la Argentina (Historia, Lengua y literatura, Educación cívica y Física), y señala que el atraso más significativo se producía en Historia:

Nuevas corrientes que han tenido influencia en las Ciencias Sociales en general y en la Historia en particular, y que incluso han entrado en la escuela media a través de otras asignaturas, por ejemplo el estructuralismo en Lengua y Literatura, no se hicieron sentir en la enseñanza de la Historia. ${ }^{11}$

Según Cecilia Braslavsky la ruptura con la tradición historiográfica liberal difiere entre los países de América Latina y lo mismo ocurre con el grado de penetración de las nuevas corrientes historiográficas en los libros de texto. En su artículo de $1989^{12}$ consideraba que la ruptura con la historiografía liberal comenzó antes en Argentina pero fue más zigzagueante que, por ejemplo, en Colombia, donde es más reciente pero más continua. Respecto de la incorporación de las nuevas corrientes historiográficas, en Colombia y México marcaba una tendencia fuerte de los historiadores modernos a trabajar en la elaboración de libros de texto que para entonces no se percibía en la Argentina. En su trabajo de 1991 hacía un balance de los libros de texto argentinos en el que señalaba que seguían centrándose en los hechos políticos y militares y que si incluían aspectos económicos o sociales, no brindaban elementos para comprender los procesos ni relacionarlos con problemáticas del presente.

Si los historiadores no se preocupan por procesar su producción y ponerla al alcance de la escuela y los políticos tampoco se ocupan de los programas, ¿de dónde se espera que provengan los impulsos para la modificación de los libros de texto en circulación?. ${ }^{13}$ 
Concluía señalando la necesidad de que llegue a la escuela mucho más de la producción académica, ya que:

los libros de texto no son más que el emergente visible de un gravísimo proceso de deterioro de la calidad de todo el sistema educativo argentino... ${ }^{14}$

Hilda Lanza en su trabajo de 1991, también remarcaba la escasa renovación de los programas de estudio y los libros de texto en Historia. ${ }^{15}$

Pero el distanciamiento entre la historiografía académica y la historia que se enseña en las escuelas no existió desde siempre. La crisis económica de 1930 constituye un punto de inflexión. Allí comienza, como sostiene Miguez:

una lenta corrosión del proyecto hegemónico ideológico liberal... En los cincuenta años siguientes la arena ideológica se transformó en un intenso campo de batalla entre distintos proyectos - el integrismo católico, el nacionalismo populista, el socialismo radicalizado, el modelo liberal aún persistente y diversas variantes y combinaciones de éstos... ${ }^{16}$

Ossana ${ }^{17}$ coincide con Miguez y señala que la indefinición de esta lucha y la inercia contribuyeron a preservar la continuidad del dominio liberal sobre los programas oficiales y los textos escolares.

En 1991 Hilda Lanza investigó el lugar que ocupa América Latina en nuestros libros de texto y encontró que se le asignaba muy poco espacio, y que los contenidos están descontextualizados y atomizados. Sostenía que las referencias a la región no eran más que frases sueltas y las problemáticas específicas permanecían sin tematizar.

... América Latina permanece detenida en el siglo XIX ... A partir del inicio del siglo XX los acontecimientos de la historia latinoamericana desaparecen del texto, comienza para la historia nacional las sucesiones presidenciales... desconectadas de los acontecimientos internacionales; pero fundamentalmente desconectadas de la historia de América Latina.

Tanto en la propuesta oficial como en la editorial, ${ }^{18}$ la información es escasa y, para el siglo XX se limita prácticamente a referir conflictos entre países de la región:

... dicho conocimiento [el referido a la región] no contempla la génesis y el desarrollo de los problemas presentes de la región... impidiendo... la comprensión e identificación de algunos procesos continentales, regionales y nacionales. ${ }^{19}$ 
Miguez $^{20}$ por su parte esquematizaba el panorama de los textos según tres modelos: acontecimental-institucionalista, enciclopedista y globalizante-interpretativo. En el primero los temas se amplían e incluyen cuestiones económicas y sociales, pero se sigue dando prioridad a los aspectos institucionales. En el enciclopedista, ya no hay una limitación a los aspectos institucionales, los textos incluyen información sobre aspectos más variados de la realidad pero sin articularlos en una explicación coherente. En el modelo globalizante-interpretativo, los distintos aspectos de la realidad se articulan en una interpretación haciendo inteligibles los procesos históricos. En 1992 sostiene que predominan los dos primeros modelos.

L. A. Romero y L. De Privitellio ${ }^{21}$ vinculan las innovaciones en los textos con un cambio en el perfil de los autores: la incorporación de egresados de Universidades Nacionales que desarrollan tareas de docencia e investigación en esos centros. Aunque, como señala Privitellio:

hasta fines de los ochenta las novedades se limitaron al ingreso de temáticas de la historia social y económica las que, a pesar de su importancia, no lograron quebrar la hegemonía del relato político tradicional", por lo que "los manuales de los primeros años del período democrático yuxtapusieron los temas socioeconómicos a los esquemas ya conocidos. ${ }^{22}$

Pero las tendencias de cambio que se insinuaban en 1990 avanzaron, ganaron en profundidad y se generalizaron al conjunto de la propuesta editorial.

Graciela Frigerio define un doble proceso de envejecimiento y desgaste de los contenidos. Por un lado, el envejecimiento biológico que alude a la relación con el desarrollo del conocimiento en el ámbito académico y por otro, el envejecimiento moral, con respecto al conocimiento que resulta significativo para una sociedad en un momento dado. ${ }^{23}$ En esta línea, podemos afirmar que los contenidos de los textos de historia anteriores a 1990 envejecieron desde ambos puntos de vista. También podemos justificar la necesidad de que los contenidos de la historia económica y social integren los libros de texto desde una perspectiva ausubeliana. ${ }^{24}$ Lea Vezub nos aporta una aplicación del concepto de relevancia que resulta pertinente para justificar la inclusión de tales contenidos en sus versiones más actualizadas.

Si la categoría de significatividad ... se refiere a la dimensión individual, la de relevancia es su contraparte... se ubica en el otro polo de la problemática relativa a los criterios de selección de contenidos: la dimensión social... De allí que decidir la relevancia o no de un contenido sea una tarea sumamente compleja que entraña cuestiones políticas, económicas y culturales, además de las netamente educativas o pedagógicas. ${ }^{25}$ 
Desde este punto de vista, los de la historia económica y social son hoy contenidos relevantes.

Hilda Sábato y Hans-Joachim König ${ }^{26}$ trabajaron las formas específicas en que se presenta la historia económica y social en los libros de texto. Ambos analizan la historia argentina de la segunda mitad de siglo XIX, en textos anteriores a 1990. Según Hilda Sábato:

las formas de presentación de los factores de desarrollo económico y social argentinos en los textos de Historia... [constituyen] un no-tema, puesto que sólo se ofrecen referencias escasas, fragmentadas, que ocupan un lugar marginal...

La información se presenta suelta, seleccionada con un criterio poco claro, con énfasis en lo institucional. Subraya también la notable desactualización bibliográfica así como la presencia de errores gruesos de información. Por lo general, no se mencionan los sectores económicos y sociales; el único actor que aparece es el Estado o, más bien, el gobierno. Las cuestiones económicas y sociales se presentan como historia sin sujeto. Se utilizan formas impersonales para referir procesos económicos y sociales (es la agricultura, o la red ferroviaria la que se expande). Otras veces, se limita el tratamiento de procesos al enunciado de las leyes que lo regulan (por ejemplo, para el proceso inmigratorio se limitan a citar la ley de inmigración). Finalmente, en el balance de Sábato, son libros desprovistos de lógica explicativa o interpretativa y más aún de versiones alternativas sobre un tema. Mientras las secciones dedicadas a la historia política e institucional se organizan según un eje cronológico, en las secciones de economía y sociedad hay una simple sucesión arbitraria de temas...

Un párrafo sucede al otro sin que se pueda adivinar cómo se conectan entre sí... ${ }^{27}$

König hace críticas muy semejantes a las de Sábato. Señala que los aspectos económicos y sociales se presentan sin coordinación, sin explicitar sus interrelaciones y efectos a largo plazo. Sólo se enumeran acontecimientos, lo que conduce frecuentemente a la formulación de un mero inventario. Además, cuando se mencionan factores económicos se lo hace sólo en forma sumaria y a menudo sin una crítica. Tal panorama es, a su entender, producto de un ocultamiento deliberado y sistemático. ${ }^{28}$

Los trabajos de investigación se detienen en los libros de texto editados antes de 1990, y coinciden en señalar para ese año un cambio importante con la aparición del libro Historia 3 de A. Jáuregui y otros. ${ }^{29}$ La falta de investigaciones más recientes es 
preocupante porque a partir de entonces se produjeron grandes cambios en la propuesta editorial que se profundizaron aún más con la reforma educativa.

\section{El análisis de lo económico y lo social en la disciplina histórica}

En los últimos 50 años la disciplina histórica sufrió importantes transformaciones. La "nueva historia", producto de esos cambios, se ha instalado y difundido con ritmos diferentes y particularidades nacionales en la mayor parte del mundo occidental. En un primer momento la historia económica y social, y más recientemente la historia cultural, intelectual, de las ideas y las prácticas, se ha impuesto por sobre la historia políticoinstitucional. ${ }^{30}$

El fin de los años '70 marca un quiebre, cuyo punto de partida es sin duda el agotamiento de la capacidad explicativa de los grandes relatos - marxismo y estructuralismo entre otros- durante los '50 y los '60. Por su lado, los '80 no fueron propicios para las ortodoxias de ningún signo.

Con la crisis de los análisis estructurales y los grandes relatos surgió un renovado interés por los individuos, sus relaciones sociales, elecciones, comportamientos y percepciones sobre el proceso histórico que les toca vivir. Se incluyeron nuevos temas -la familia, la infancia, las mujeres, la vida cotidiana, las mentalidades-, nuevas fuentes -fotografías, filmes, objetos materiales testimonios orales- y nuevos enfoques.

Los intercambios con la antropología y la lingüística se sumaron al ya habitual diálogo con la economía, la sociología y la demografía. Se plantean lecturas alternativas del pasado, modelos de análisis más complejos y matizados. Al mismo tiempo, los historiadores perdieron seguridad en cuanto a la consistencia de los resultados de sus investigaciones. $^{31}$

Otros avances fueron menos gratos para la comunidad de historiadores. Visiones más radicales, que por lo general provienen de fuera de la historia, se plantean hoy la naturaleza misma del conocimiento histórico y, lo que es más problemático para la disciplina, cuestionan el hecho de que el discurso histórico tenga un referente en una realidad externa.

Varias tendencias se mantuvieron y profundizaron, no obstante, sin solución de continuidad, desde los años '50: la apertura al diálogo con otras ciencias sociales; la idea que liga la historia a sujetos colectivos y no individuales; el uso de herramientas y técnicas de análisis más refinadas; un aumento cuantitativo de la producción de libros y revistas especializadas, de congresos y reuniones académicas; la internacionalización definitiva de los estudios históricos. 
La historiografía argentina vivió también transformaciones importantes en los últimos 40 años. En los años '60 se produce la irrupción en el mundo académico de formas de hacer historia que tratan de superar los marcos tradicionales de la historia política y diplomática, orientándose hacia una historia de cuño social. Esto se realizó en estrecha relación con los desarrollos de otras ciencias sociales (la sociología funcionalista impulsada por G. Germani y su grupo, por ejemplo), que la marcaron con su impronta. Estas transformaciones, tímidas al principio (sólo reducidas a unos grupos de la UBA- Rosario- La Plata), suelen englobarse bajo el rótulo de "Historia social".

La escalada militar que asoló a la región a partir de los años '60 tuvo un efecto disolvente sobre este proceso. Fueron destruidos los marcos institucionales que albergaban a estos nuevos grupos, y muchos de sus protagonistas debieron exiliarse. Estas tendencias no harían más que acentuarse durante las experiencias de gobiernos militares de los ' 70 .

En 1983, con la vuelta de la democracia y la normalización de universidades y centros de estudio, tiene lugar el retorno de una historiografía abierta a lo que se producía en otras latitudes (muchas veces originado en contactos personales establecidos durante los forzados exilios), que se empeñaba en establecer criterios de profesionalidad asimilables a los de la historiografía internacional. ${ }^{32}$

La llamada "historia social" dejó su marca en la historiografía de los '80 y '90, que retoma sus planteos generales y algunos interrogantes; en cambio, abandona sus temas y convicciones. Las teorías del desarrollo, el marxismo estructuralista y en general todo lo que resuene a estructuras y explicaciones omnicomprensivas, perdieron espacio.

El estallido de temas, perspectivas y fuentes característicos de la historiografía occidental actual tuvieron lugar, con sus particularidades, también en la historiografía nacional. Hoy los temas más trabajados pertenecen a la historia de las ideas, la cultura y las prácticas, y a la nueva historia política, convertida en una historia social de la política. Cada vez se recurre con mayor frecuencia a aproximaciones nuevas como la microhistoria, el análisis de redes y configuraciones, y se usan metodologías innovadoras. ${ }^{33}$

\section{Los libros de texto en la enseñanza de la historia}

La enseñanza de la historia tiene un papel clave en la construcción de valores y la formación de una conciencia colectiva. Como sostiene Luis A. Romero, el saber histórico es un instrumento poderoso porque moldea la conciencia histórica de una sociedad. El conjunto de ideas que circulan en una sociedad y conforma el imaginario es más complejo y contradictorio que lo que aparece en los libros de texto. 
Pero no es ajeno a ella, pues lo que aparece en los libros de historia, geografía y civismo arraiga legitimamente en ideas fuertes en nuestra sociedad. ${ }^{34}$

No es necesario abundar sobre la importancia del texto en la enseñanza de la historia, su peso decisivo y la medida en que condiciona la actividad del docente. Sin duda, los libros de texto son los materiales curriculares con mayor incidencia para el aprendizaje en el aula. Su rol directivo y configurador de la práctica en el aula los hace diferentes de los demás recursos. También fuera del aula porque la mayor parte del tiempo que los alumnos dedican a los deberes está ocupada por los libros de texto .

Es el recurso del curriculum que ejerce mayor influencia en los profesores para la toma de decisiones sobre la planificación. Más aún en contextos de reforma educativa, porque muchas veces los docentes resuelven las incertidumbres que generan los cambios en la propuesta oficial a través de la elección de un libro de texto que parece brindar la adaptación de los currículos al aula. Condicionan al docente en la selección de contenidos pero también en la forma de enseñar, al punto que muchos docentes se someten pasivamente al currículum que reflejan los textos.

Aunque fueron y son objeto de grandes polémicas, es cierto que hasta los profesores que más los critican siguen usándolos en su trabajo cotidiano. ${ }^{35} \mathrm{La}$ dependencia de los alumnos hacia el libro de texto es mayor a medida que se desciende en la escala socioeconómica.

Esta tendencia avalaría la necesidad de que los historiadores y los investigadores en didáctica se aboquen a su análisis y mejoramiento. ${ }^{36}$

Por cierto, no podemos avanzar en el análisis sin tomar en cuenta que los libros de texto resultan del cruce de distintas lógicas y no exclusivamente de consideraciones de tipo didáctico. Como sostiene S. Grinberg:

en el proceso de producción de los textos escolares se entrecruzan factores de diversa índole: políticos, económicos, culturales, etc. El estado de la historiografía, las exigencias de la reforma educativa y la competencia en el mercado editorial intervienen condicionando su producción. ${ }^{37}$

Resultado del conjunto de demandas, los libros de texto cambiaron no sólo desde el punto de vista de los contenidos; su función misma en los procesos de enseñanzaaprendizaje es diferente hoy. Dejó de ser usado exclusivamente como material de estudio y valorado según la cantidad y calidad de la información que brinda. Hoy ocupa el 
lugar de herramienta en el aula. Este nuevo rol valoriza características diferentes de los libros de texto, tales como la presencia de fuentes, ${ }^{38}$ transcripciones de fragmentos de especialistas, actividades, ilustraciones, ejercicios de observación de imágenes, cuadros estadísticos, mapas etc. El lenguaje visual juega un rol cada vez más importante tratando de ofrecer el mismo contenido en múltiples lenguajes. ${ }^{39}$ Será necesario entonces analizar también si los libros de texto logran presentar los aspectos económicos y sociales en esta multiplicidad de lenguajes.

Finalmente, el proceso de integración regional hace necesario evaluar la medida en que los libros de texto introducen esta escala en los procesos históricos.

\section{Los libros de texto actuales}

Con relación a los contenidos que ofrecen los libros de texto actuales, los cambios más importantes consisten en la incorporación de contenidos de Historia económica y social, el enfoque procesual y el haber resuelto en buena medida la cuestión de la desactualización bibliográfica propia de los textos anteriores a 1990. Pero esto no implica que se haya resuelto todo el problema. Incorporación no necesariamente implica integración. A su vez, ésta no se da de la misma manera en todos los libros.

Los CBC de Ciencias Sociales son muy amplios y completos, además están estructurados según la lógica propia de cada disciplina. Por lo tanto, es necesario hacer un recorte, una selección y organización gradual de contenidos. Es decir, se impone la toma de una serie de decisiones. Ahora bien, ¿quién lo hace? Si estas decisiones no se toman cuando se diseña la propuesta oficial, terminan siendo tomadas por las editoriales; y el docente sólo decide qué propuesta editorial elige.

\section{Corpus de textos analizados}

Para este trabajo seleccionamos textos publicados a partir de la reforma educativa y dimos preferencia a los más recientes. El corpus resultante se compone de 5 textos: Alonso M. E., Elisalde R., Vázquez E.: Historia de las sociedades. América en los siglos XVIII y XIX, 3er ciclo de EGB, Aique.

Bustinza J. A., Bustinza P., Franco R.: Ciencias Sociales 8, Serie Integrar, A-Z editora. Fradkin R., Boixados R., Schaposchnik A., Figueiras R., Barros C., Saab J., Gil Lozano C.: El libro de la sociedad en el tiempo y el espacio 8, Estrada.

Rossi P., Cortiñas N., Francisco A. C., Fernández S.: Ciencias Sociales 8. Convivencias hoy, Oxford-Harla. 
Cattáneo L., Cattaruzza A., Paz G., Rocchi F., Celotto A.: Ciencias Sociales. Historia 8, Santillana.

\section{Análisis de la propuesta editorial}

Nos proponemos ver en qué medida los problemas señalados como cuentas pendientes han sido superados por los textos actuales. En primer lugar se describen las características generales, atendiendo principalmente al espacio dedicado a los diferentes temas. En segundo lugar, observamos el estilo general de los textos y el peso relativo de la más "tradicional" historia política respecto de la económica y social y los esquemas de argumentación de los procesos históricos que se ofrecen. En tercer lugar, evaluamos la incorporación de un perspectiva regional y continental de análisis. Por último, focalizamos el tratamiento del período revolucionario y analizamos allí la inclusión de aspectos económicos y sociales, el peso de los diferentes factores en las explicaciones causales, los conceptos que se utilizan, la caracterización de los actores sociales y sus intereses, etc.

\section{Los problemas de espacio}

En una primera mirada sobre la propuesta editorial actual, llaman la atención los problemas de espacio. Los textos seleccionados desarrollan la historia de Europa y América desde comienzos del siglo XV -salvo en Oxford que comienza en el siglo XI- y llega hasta mediados o fines del XIX, un promedio de 500 años, para ser trabajados en un año escolar. Tres de los cinco libros que analizamos incluyen, además de Historia, contenidos de Geografía y Formación Ética y Ciudadana. Existe una importante densidad temática en los textos, es decir, escasez de espacio disponible para analizar cada uno de los temas incluidos en el índice. En un trabajo anterior ${ }^{40}$ realizamos un análisis comparativo de la propuesta editorial argentina y la uruguaya y encontramos marcados contrastes. Los textos uruguayos consultados ${ }^{41}$ desarrollan exclusivamente contenidos de Historia y cubren un período de poco menos de 100 años (1730-1820 aproximadamente).

En el Cuadro 1 del anexo, una serie de indicadores permite comparar con más precisión estas diferencias. Calculamos el espacio hipotéticamente disponible en cada texto para desarrollar 10 años de historia. Otro modo de expresar la misma relación entre contenido y espacio es el cálculo de la cantidad de años de historia que deberían ser tratados en 10 páginas de texto. ${ }^{42} \mathrm{~A}$ partir de estos indicadores es posible clasificar los textos en dos grupos. Los menos densos son los de Santillana, Aique y A-Z, que 
deberían desarrollar entre 30 y 40 años de historia en 10 páginas. Y los más densos son Oxford y Estrada que deberían tratar entre '70 y '90 años en el mismo espacio. ${ }^{43}$

\section{Historia social y revolución en los textos escolares}

Hoy existen cambios importantes respecto de la situación que se describe para comienzos de los noventa. Hay un esfuerzo por incorporar aportes y novedades provenientes de la historiografía académica que acorte la distancia entre ésta y la historia que se enseña. Entre estos cambios se observa un abandono progresivo del eje cronológicopolítico como organizador exclusivo de la narración, con explicaciones multicausales que hacen inteligible los procesos. Una cuestión pendiente es el balance de estos esfuerzos: cómo se integraron los nuevos contenidos y en qué medida fueron adecuados didácticamente.

Proponemos el análisis cualitativo acotado al tratamiento del proceso de las revoluciones de independencia en los libros de texto. Intentamos así dar un panorama de las modalidades de integración (o no-integración) de los contenidos que complementan nuestro análisis cuantitativo. Partimos de una medición, el espacio dedicado al tema, nos proponemos ver cómo se distribuye el espacio disponible entre los diferentes contenidos y la medida en que los más tradicionales son integrados con los más nuevos.

Los textos escolares dedican un promedio de 12 páginas al análisis de la revolución de independencia para el caso nacional. ${ }^{44}$ Es obvio que el espacio disponible, o su falta, condiciona el tratamiento de los temas. Así, en los textos de mayor densidad se emplea mayor cantidad de conceptos que no se explican, hay menos ejemplos; en suma, son más abstractos y difíciles de leer y comprender.

En el texto de Santillana se desarrolla con profundidad el sistema económico colonial que va a servir de marco para la explicación del proceso de revoluciones hispanoamericanas. Pero este desarrollo crece a expensas del análisis de los acontecimientos en el Río de la Plata que tiene muy poco espacio. En la propuesta de Oxford el relato de los hechos políticos de la revolución es muy minucioso pero hay pocas referencias a los aspectos socioeconómicos o al proceso en su escala continental.

En general, los textos presentan un problema de escala entre los contenidos que se incluyen y el espacio disponible; de lo que resulta en muchos casos la mención sin desarrollo y falta de integración, o la omisión de aspectos y procesos que sería pertinente tratar. Consideramos que esta situación es en parte imputable a la extensión de los CBC y, en parte, a la necesidad estratégica de las editoriales de producir libros que cubran todos los temas para competir en el mercado. ${ }^{45}$ 
La propuesta editorial argentina es heterogénea. Citamos como ejemplo dos casos de opciones extremas: Aique y Oxford. En el texto de Aique el tema económico está permanentemente presente. El proceso revolucionario se explica por razones económicas, se identifican claramente los intereses económicos de los diferentes actores sociales y se analizan sus complejas relaciones con los actores que en cada etapa detentan el poder político. Sin embargo, y en contraste con este amplio tratamiento de la historia social y económica, la historia política y militar del período ocupa un lugar marginal con algunas referencias a personajes individuales y omisiones significativas. El libro de Oxford, a la inversa, muestra un relato centrado en lo político con escasas referencias a procesos sociales y económicos. Ocupa el $80 \%$ del espacio total dedicado a la historia de América Latina para el período 1776-1826 con la revolución de independencia e incluye importantes apartados con el desarrollo de las guerras y campañas militares. ${ }^{46}$

Entre la versión más innovadora de Aique y la más tradicional de Oxford se ubica el abanico de propuestas. En los textos de Santillana y A-Z se observa preocupación por caracterizar los grupos sociales que intervienen en las revoluciones americanas, y articular la argumentación en torno de sus conflictos. Sin embargo, esta preocupación por lo social no desplaza a la historia política, que conserva un lugar importante. En el texto de Estrada encontramos que se hacen referencias a lo económico y social, aunque se mantiene lo político como ordenador del relato.

Todos los libros tratan las revoluciones hispanoamericanas desde una perspectiva continental, como parte del proceso de difusión de las revoluciones liberales. Pero la relación entre el caso nacional y el proceso continental varía en cada caso. La propuesta de Aique tiene una descripción de las revoluciones hispanoamericanas que sirve de contexto para el desarrollo del caso nacional. Santillana, Estrada y A-Z presentan un esquema opuesto: tratamiento privilegiado del proceso continental y el caso nacional como un apartado menor. En este punto Santillana merece una mención especial: el espacio dedicado al Río de la Plata es prácticamente inexistente. Oxford trata con detenimiento el caso nacional pero casi no considera la escala continental.

Creemos que la incorporación de la perspectiva continental está más ligada al desembarco de la historiografía académica en los libros de texto que a los intentos de fortalecer la integración regional desde la enseñanza de la Historia y la Geografía. En realidad, el proceso de integración regional que dio lugar a la creación del Mercosur todavía no llegó a los libros de texto. Por ejemplo, se dedican párrafos inconexos y en muchos casos anodinos a los hechos simultáneos de la Banda Oriental, aunque el caso de Brasil $^{47}$ es tratado, en general, con mayor amplitud. 
Una evaluación de conjunto muestra que aun cuando hay un consenso bastante general acerca de lo que debe ser un texto actualizado pedagógicamente, los resultados son desparejos. Una serie de factores puede explicar la distancia entre propuestas innovadoras y resultados efectivos. Nuestro sistema educativo atraviesa una crisis de adaptación a las propuestas oficiales de reforma, que se superpone con problemas de la escuela media de más larga data. Es de esperar, en este contexto, que la construcción de mediaciones adecuadas entre la propuesta oficial y la práctica docente se dé en un proceso lento y complejo, una mezcla de tradición e innovación que se refleja en los libros de texto analizados. Otro factor a considerar son las transformaciones en las empresas editoriales (la globalización de las empresas, aparición de los departamentos de marketing, aumento de la competencia) y la medida en que la lógica de mercado puede producir efectos distorsivos. Por ejemplo, creemos que la excesiva densidad temática de algunos textos es efecto de estrategias editoriales que intentan hacer su producto más competitivo incluyendo en los libros "todos" los CBC para atraer a un docente desorientado frente a la reforma educativa.

Respecto de los textos que se editaban a principios de los noventa, los libros actuales representan un avance innegable. La economía, la sociedad y las relaciones entre las distintas dimensiones fueron incorporadas al relato. La magnitud de la desactualización bibliográfica se ha reducido considerablemente, aparecen autores vinculados al grupo de la renovación historiográfica de los '60, destacándose entre ellos J. L. Romero y de T. Halperín Donghi. Además se propone la lectura de historiadores que desarrollan su actividad en los centros de producción historiográfica más activos y son referencia obligada en la historiografía académica como son Sábato, Tandeter, L. A. Romero, Oszlak y Chiaramonte. También se incorpora bibliografía producida en otras partes del mundo, como las obras de Hobsbawm, Lynch, Wachtel, Murra, entre otras. De todos modos, los más modernos desarrollos de la historiografía, como historia cultural, historia de las prácticas, aún no aparecen.

Sin embargo, una mirada a los capítulos dedicados a las revoluciones hispanoamericanas muestra que la historia económica tiene un espacio menor que otros aspectos. Una aproximación cuantitativa muestra que en la mayoría de los textos las referencias a la economía son aisladas, ocupan unas pocas páginas o aparecen más yuxtapuestas que integradas en el relato (ver cuadro $\mathrm{N}^{\circ} 2$ del anexo). Esta afirmación tiene por supuesto matices y excepciones.

Creemos que la incorporación de las novedades historiográficas no se debe hacer a expensas de la llamada historia tradicional. Por el contrario, pueden combinarse las innovaciones de la disciplina, con aquellas otras aproximaciones, lo que permite a los 
alumnos una integración más acabada de las múltiples facetas que componen las experiencias humanas.

Veamos ahora, en una acercamiento más cualitativo, qué cuestiones económicas se incluyen y de qué forma.

En todos los libros se dedica un espacio considerable a explicar la organización económica que la corona española impuso en América. Aun cuando esto no forma parte estrictamente de la economía en el proceso revolucionario, señala un interés por mostrar el sistema económico que, con transformaciones, será heredado por los nuevos países independientes.

En la mayoría de los libros, los aspectos económicos forman parte del relato central y son un factor explicativo de los sucesos del período revolucionario. En algunos como el de Aique es el factor explicativo central, mientras que en otros constituye un factor estructurante que se combina para explicar los procesos; es el caso de Santillana, Estrada y A-Z. El sistema económico colonial, las reformas económicas de los Borbones, los efectos del monopolio y del librecambio, y las consecuencias económicas de las luchas por la independencia, se tratan con mayor o menor detenimiento en todos los textos.

Ahora bien, la incorporación de estos temas no resuelve todo el problema. Es necesario ver en qué medida se logró presentarlos de manera accesible para los destinatarios. De nuestro análisis surge que en la mayoría de los casos la adecuación didáctica de los desarrollos de la historia económica es una cuenta pendiente. Los nuevos contenidos se han incorporado sin mayores adaptaciones. Los procesos económicos, los conceptos de la economía y su análisis en general no están suficientemente explicados, las relaciones entre factores no se explicitan, se mantienen muchos sobreentendidos. Con frecuencia los actores sociales no se definen con claridad y se desdibujan a lo largo del relato en categorías más generales. A veces, a las complejidades de los contenidos se suman otras, que derivan de un vocabulario y una sintaxis que no se adecuan al lector.

Respecto de los contenidos de historia económica y social se produce un desequilibrio entre el nivel de conocimientos de los que parte el lector y el necesario para comprender el texto. El efecto de este desequilibrio puede resultar en una merma considerable en la comprensión. Para que los alumnos activen sus conocimientos previos, la distancia entre el punto de partida y lo que debe adquirir es un factor determinante. Cuando la distancia es excesiva el alumno recurre a la memorización mecánica del nuevo contenido. ${ }^{48}$

Cuando se incluye un desarrollo de las doctrinas económicas - mercantilismo, fisiocracia, liberalismo- éste forma parte de capítulos de historia europea. No se intenta relacionar los cambios económicos con la historia de las ideas económicas. Por el contrario, se presenta una estrecha asociación entre las ideas políticas de la revolu- 
ción francesa y americana - las teorías modernas de la legitimidad del gobierno y los civiles- y de las revoluciones hispanoamericanas. Aique constituye una excepción puesto que las nuevas ideas económicas se retoman para caracterizar la élite revolucionaria de Buenos Aires.

Conceptos económicos como sistema productivo, mercado internacional, economía abierta, economía extractiva, monopolio están poco explicados. Muchas veces se incluyen presuponiendo que el alumno los tiene incorporados.

Dentro de los conceptos económicos los vinculados a la producción, el comercio y la política económica tienen un desarrollo un poco mayor que los referidos a cuestiones financieras y monetarias. Así, el concepto de deuda externa, el sistema de crédito internacional, la inflación, respaldo y devaluación monetaria no se explican. Sí , comercio colonial, monopolio, librecambio, "larga espera".

En Santillana y Aique se desarrollan los intereses de los diferentes grupos sociales y las oposiciones entre intereses regionales. Sin embargo, los intereses de comerciantes y hacendados se desdibujan en el tratamiento del proceso revolucionario, donde el principal conflicto de intereses tiene un clivaje no económico, allí la oposición es entre españoles (que pueden ser hacendados, comerciantes, funcionarios del estado o empresarios mineros) y criollos.

En la mayoría de los casos no hay glosario que explique los términos de difícil comprensión. Por lo general se incluyen muy pocos cuadros o ilustraciones referidos a temas económicos.

En cuanto a las actividades, en los casos de Santillana y Aique se insiste en formular preguntas que apuntan a aspectos de la economía o bien se propone el análisis de párrafos extraídos de especialistas. En estos casos, si bien hay actividades orientadas a los aspectos económicos y sociales son todas de tipo discursivo. No se logran presentar los aspectos económicos en diferentes lenguajes.

La presentación de los factores económicos en las explicaciones de la revolución se puede esquematizar de la siguiente manera.

\section{Procesos económicos generales o de más larga duración:}

a) La instalación de un sistema económico colonial que extrae riquezas (a través de sistemas de explotación económica tan diversos como la mita en las minas, la plantación con trabajo de esclavos en zonas tropicales o la hacienda ganadera) y plantea para los americanos problemas estructurales (como las consecuencias del sistema monopólico de comercio, la escasa relación entre las regiones o cuestiones vinculadas a la administración) y que no se resolvieron con las sucesivas reformas. 
b) El drenaje de las riquezas extraídas desde España hacia Gran Bretaña y Holanda.

c) La desarticulación de las economías por la revolución y las guerras subsiguientes, "la larga espera" que media entre los intentos de organización económico-administrativos y la inserción efectiva en el mercado mundial.

\section{Coyunturas económicas presentadas como factores desencadenantes:}

a) Las reformas económicas y administrativas implementadas por los Borbones que provocan en América conflictos de intereses entre diferentes sectores;

b) El bloqueo económico de Inglaterra a España, que produce la virtual interrupción del comercio colonial y cuyos efectos no pudieron solucionarse aún con el permiso posterior de comerciar con navíos neutrales.

c) Los efectos económicos de la invasiones inglesas, que permiten experimentar los beneficios del libre comercio.

\section{A modo de balance}

Los contenidos de la historia económica y social han sido efectivamente incorporados y ocupan, aunque variable, un lugar importante en los de textos actuales.

La distancia que en los ' 80 separaba a la historiografía académica de los libros de textos creemos que ha sido considerablemente acortada y que esto responde en buena medida al cambio de perfil en los autores.

Surgen nuevas cuentas pendientes Una de ellas es la adecuación didáctica de los conceptos y procesos de la historia económica y social, pues muchos conceptos permanecen en un nivel muy abstracto o se utilizan sin ser explicados. La multicausalidad y la relación jerárquica de causas permanecen como supuestos. Faltan ejercicios, actividades y trabajo con imágenes para estos temas.

Hasta el momento de la independencia la economía ocupa un lugar fundamental, para el período 1810-1880, en cambio, su lugar se desdibuja. En este punto creemos que los libros de texto no hacen más que reflejar las "lagunas" de la historiografía académica en la que ése es un período poco estudiado desde el punto de vista de la historia económica y social.

Los intentos de integración entre contenidos nuevos y los de más larga tradición obtienen resultados muy desparejos. Por dificultades para articular algunos contenidos tradicionalmente incluidos en los libros de texto frecuentemente se comete lo que consideramos un error grave: desecharlos. Es el caso de temas como la diplomacia, las relaciones internacionales, y las biografías entre otros. 
Los problemas de espacio y densidad son de magnitud. Creemos que pueden explicarse por las características de la propuesta oficial vigente así como por las estrategias comerciales de las empresas editoriales. Estos problemas de relación contenidos-espacio en los libros de texto son importantes pues reaparecen en la práctica concreta entre los contenidos a desarrollar y el tiempo disponible para hacerlo.

La escala continental de los procesos de independencia está incluida en los libros de texto. En cada propuesta juega un papel diferente. En algunos textos contextualiza el desarrollo del caso nacional mientras que en otros, crece a expensas de éste.

La perspectiva regional permanece ausente y constituye, por lo tanto, otra cuestión pendiente. Creemos que los libros de texto incorporan la perspectiva continental como efecto de la vinculación mas estrecha con la historiografía académica. El proceso de integración regional, en cambio, aún no produjo efectos considerables en los libros de texto. Todavía puede encontrarse en los manuales actuales visiones de un "otro" hostil.

Dada la importancia de los libros de texto sería deseable que en un futuro cercano se multipliquen las investigaciones que los toman como objeto. Es de esperar que futuros estudios cubran la presentación de otros períodos de la historia.

En este análisis algunos textos aparecen como mejores que otros. Sin embargo, si abarcáramos otros items tendientes a detectar cómo se incluyen las cuestiones económicas y en qué medida se adecuan a las posibilidades de comprensión de los estudiantes, los resultados serían diferentes. En una segunda instancia, al considerar la forma en que se integraron, surgirían conclusiones diferentes. De todos modos, es posible que la comprensión de la historia económica y social deba realizarse desde la complejidad y no desde la simplificación excesiva y, por lo tanto, haya que revisar en qué momento del diseño se incluyen. 


\section{Anexo}

Cuadro 1: Características generales de los textos y cálculo de densidad

\begin{tabular}{|c|c|c|c|c|c|}
\hline & $\begin{array}{l}\text { Santillana } \\
\text { Historia } 8\end{array}$ & $\begin{array}{r}\text { Aique } \\
\text { América en los } \\
\text { S. XVIII y XIX }\end{array}$ & $\begin{array}{r}\text { Oxford } \\
\text { Ciencias } \\
\text { Sociales } 8\end{array}$ & $\begin{array}{r}\text { Estrada } \\
\text { El libro de la } \\
\text { Sociedad } 8\end{array}$ & $\begin{array}{r}\text { A-Z Editoria } \\
\text { Ciencias } \\
\text { Sociales } 8\end{array}$ \\
\hline $\begin{array}{l}\text { Contenido } \\
\text { por áreas }\end{array}$ & $\begin{array}{l}\text { Historia } \\
325 \text { pp }\end{array}$ & $\begin{array}{l}\text { Historia } \\
224 \text { pp }\end{array}$ & $\begin{array}{r}\text { Historia, geogra- } \\
\text { fía, formación } \\
\text { ética y ciudada- } \\
\text { na } 302 \text { pp }\end{array}$ & $\begin{array}{r}\text { Historia, geogra- } \\
\text { fía, formación } \\
\text { ética y ciudada- } \\
\text { na } 303 \text { pp }\end{array}$ & $\begin{array}{r}\text { Historia, geogra- } \\
\text { fía, formación } \\
\text { ética y ciudada- } \\
\text { na } 427 \text { pp. }\end{array}$ \\
\hline $\begin{array}{l}\text { Contenidos } \\
\text { de historia }\end{array}$ & $\begin{array}{l}\text { Europa y Améri- } \\
\text { ca } 1400-1900 \\
\text { (500a.) } 325 \mathrm{pp}\end{array}$ & $\begin{array}{r}\text { Europa y Améri- } \\
\text { ca } 1400-1850 \\
\text { (450a.) } 224 \text { pp }\end{array}$ & $\begin{array}{r}\text { Europa y Améri- } \\
\text { ca } 1000-1820 \\
\text { (820a.) } 177 \mathrm{pp}\end{array}$ & $\begin{array}{r}\text { Europa y Améri- } \\
\text { ca } 1400-1900 \\
\text { (500a.) } 139 \mathrm{pp}\end{array}$ & $\begin{array}{r}\text { Europa y Améri- } \\
\text { ca } 1400-1900 \\
\text { (500a.) } 234 \mathrm{pp}\end{array}$ \\
\hline Densidad * (c) & $3,25 p$ & $2.49 p$ & $1.08 p$ & $1.39 p$ & $2.34 p$ \\
\hline Densidad $* *(c)$ & 30.77 a. & 40.16 a. & 92.59 a. & $71.94 \mathrm{a}$ & $42.74 \mathrm{a}$ \\
\hline
\end{tabular}

* Expresada en espacio disponible para 10 años de historia (c)

** Expresada en años que deben ser cubiertos en 10 páginas del texto (c)

\section{Cálculo de densidad}

En el presente trabajo se denomina densidad a la relación que existe entre los contenidos hipotéticamente cubiertos por un texto y la cantidad de páginas del mismo. Los contenidos cubiertos se calculan multiplicando el número de años hipotéticamente tratados en un texto -según su índice-, por los 2 espacios geográficos considerados (Europa y América). Se supone en esta ecuación que los acontecimientos históricos relevantes se distribuyen de modo homogéneo en el tiempo. Se supone, además, que las historias de Europa y América poseen un peso equivalente y deben ser tratadas en consecuencia. No pretendemos sostener la validez ontológica de los supuestos, sólo deseamos señalar su pertinencia a efectos de las comparaciones que permiten realizar. Consideramos que, no obstante las objeciones que pueden presentarse al uso de estos supuestos, de los cálculos realizados se obtienen indicadores útiles para establecer comparaciones entre los textos.

Las fórmulas aplicadas son:

\begin{tabular}{|c|c|}
\hline Densidad expresada & Cantidad de páginas disponibles \\
\hline en años que deben ser cubiertos & Período cubierto (años) X 2 \\
\hline en 10 págs. de texto & Europa y América \\
\hline
\end{tabular}


Densidad expresada

Período cubierto (años) X 2

en años que deben ser cubiertos

$$
=\frac{\text { Europa y América }}{\text { Cantidad de páginas disponibles }}
$$

x 10 años

en 10 págs. de texto

Cuadro 2: Historia de América colonial y revoluciones hispanoamericanas.

\begin{tabular}{|c|c|c|c|c|c|}
\hline & $\begin{array}{l}\text { Santillana } \\
\text { Historia } 8\end{array}$ & $\begin{array}{r}\text { Aique } \\
\text { América en los } \\
\text { S. XVIII y XIX }\end{array}$ & $\begin{array}{r}\text { Oxford } \\
\text { Ciencias } \\
\text { Sociales } 8\end{array}$ & $\begin{array}{r}\text { Estrada } \\
\text { El libro de la } \\
\text { Sociedad } 8\end{array}$ & $\begin{array}{r}\text { A-Z Editoria } \\
\text { Ciencias } \\
\text { Sociales } 8\end{array}$ \\
\hline $\begin{array}{l}\text { Espacio para historia de } \\
\text { América Latina } \\
1776-1826 \text { (a) }\end{array}$ & $26 \mathrm{pp}(\mathrm{g})$ & $30 \mathrm{pp}$ & $40 \mathrm{pp}$ & $18 p p$ & $42 p p$ \\
\hline $\begin{array}{l}\text { Análisis del sistema } \\
\text { económico colonial }\end{array}$ & Sí & Sí & $\begin{array}{r}\text { referencias } \\
\text { aisladas }(h)\end{array}$ & Sí & Sí \\
\hline $\begin{array}{l}\text { Análisis de doctrinas } \\
\text { económicas (b) }\end{array}$ & No & Sí & Sí & No & Sí \\
\hline $\begin{array}{l}\text { Análisis de la revolución } \\
\text { como parte de un proceso } \\
\text { continental c) }\end{array}$ & $19 \mathrm{pp}$ & $5 p p$ & $\begin{array}{r}\text { referencias } \\
\text { aisladas } \\
1 / 2 \mathrm{pp}\end{array}$ & $6 \mathrm{pp}$ & $27 \mathrm{pp}$ \\
\hline $\begin{array}{l}\text { Análisis específico del caso } \\
\text { nacional (d) }\end{array}$ & $\begin{array}{r}\text { referencias } \\
\text { aisladas } \\
1 / 2 \mathrm{pp}\end{array}$ & $13 p p$ & $33 p p$ & $5 p p$ & $7 \mathrm{pp}$ \\
\hline $\begin{array}{l}\text { Espacio para economía en } \\
\text { proceso revolucionario (e) }\end{array}$ & $4 p p$ & $\begin{array}{r}\text { tratamiento } \\
\text { detallado }\end{array}$ & $\begin{array}{r}\text { referencias } \\
\text { aisladas }\end{array}$ & $\begin{array}{r}\text { referencias } \\
\text { aisladas }\end{array}$ & $4 p p$ \\
\hline $\begin{array}{l}\text { Espacio para guerras y } \\
\text { campañas militares (f) }\end{array}$ & $\begin{array}{r}1 / 2 \text { carilla y } \\
1 \text { mapa }\end{array}$ & $2 p p$ & $8 p p$ & $\begin{array}{r}\text { referencias } \\
\text { aisladas }\end{array}$ & $6 p p$ \\
\hline
\end{tabular}

(a) Incluye revoluciones de independencia y análisis del caso nacional. Véase definición de caso nacional en (d). (b) Doctrinas consideradas: fisiocracia y liberalismo.

(c) Sólo se toman en cuenta los apartados que analizan el proceso revolucionario a escala continental. No se cuentan las páginas que describen casos nacionales (México, Perú, Venezuela, Brasil, Uruguay, etc.).

(d) En los textos argentinos se considera como caso nacional lo ocurrido en el territorio de la actual república

(Buenos Aires, Litoral e Interior).

(e) Se consideran los contenidos de economía de los apartados (c) y (d).

(f) Se consideran los contenidos sobre guerras y campañas militares en los apartados (c) y (d).

(g) Para todos los cálculos en cantidad de páginas se consideran: texto central, textos independientes, mapas y actividades.

(b) En todos los casos Referencias aisladas remite a oraciones sueltas o párrafo menor. 


\section{Notas}

El presente trabajo forma parte de una investigación más amplia que incluye el análisis de los libros de texto de Historia y Ciencias Sociales de los países integrantes del Mercosur. En ella se analizan comparativamente cómo son presentados algunos períodos y procesos de la historia americana. ${ }^{* *}$ Facultad de Filosofía y Letras y Facultad de Ciencias Económicas - UBA.

${ }^{2}$ Ossana, E.: "Los libros de texto para la enseñanza de la historia: entre la cientificidad y las demandas político-ideológicas", en Propuesta Educativa, No 8, abril de 1993.

${ }^{3}$ Berghahn y Schissler llaman la atención sobre la escasez de trabajos en este campo en el nivel internacional. Ver Berghan, V. y Schissler, H. (ed): Perceptions of history, an analysis of school textbooks, Oxford, Berg Publishers Ltd., 1987.

${ }^{4}$ Ver, entre otros, los artículos compilados en Riekenberg, M. (comp): Latinoamérica: enseñanza de la historia, libros de textos y conciencia histórica, Buenos Aires-Madrid, Alianza,1991.

${ }^{5}$ Romero, L. A. (dir.): "Proyecto visión argentino-chilena en el sistema educativo" (VACHESE), seminario de difusión y discusión de resultados. Documento de trabajo, Buenos Aires, Facultad de Filosofía y Letras, 1998.

${ }^{6}$ Zelaya de Nader, H y Suayter de Iñigo, M.: "La inmigración en los libros de lectura: 1900-1940", en Propuesta Educativa, No 2, mayo de 1990.

${ }^{7}$ Devoto, F.: “Idea de nación, inmigración y 'cuestión social' en la historiografía académica y en los libros de texto de Argentina (1912-1974)”, en Estudios Sociales, No 3, 1992.

${ }^{8}$ Gvirtz, Silvina: “Las historias escolares argentinas y británicas. Entre silencios y agresiones”, en Propuesta Educativa, No 6, 1992.

${ }^{9}$ Werz, Nikolaus: "La presentación de las relaciones entre países industrializados y sociedades en desarrollo en los libros de texto argentinos", en Propuesta Educativa, No 8, 1993. El autor encuentra que la presentación de las relaciones entre las sociedades industrializadas y aquellas en desarrollo juega en los textos argentinos un papel muy secundario. Si bien en las nuevas ediciones [las más recientes que analiza son de 1990, o sea anteriores a la reforma educativa argentina] se hace mención al antagonismo NorteSur, sigue siendo poco claro si Argentina forma parte del Tercer Mundo, e intenta explicar este fenómeno. ${ }^{10}$ Berghahn y Schissler, op. cit.

${ }^{11}$ Finocchio, S: "Programas y textos en la historia de cuatro asignaturas de nuestra escuela media: Historia, Lengua y Literatura, Educación Cívica y Física”, en Propuesta Educativa, No 1, 1989, pág 53.

${ }^{12}$ Braslavsky, C.: "Didáctica de la historia en dos continentes", en Propuesta Educativa, № 2, 1990.

${ }^{13}$ Braslavsky, C.: “Los libros de texto en su contexto: Argentina 1975-1989”, en Riekenberg, M. 
(comp.): Latinoamérica: enseñanza de la historia, libros de textos y conciencia histórica, Buenos AiresMadrid, Alianza,1991, pág. 73.

${ }^{14}$ Braslavsky, C.: $I b$., pág 74.

${ }^{15}$ Lanza, H: "La propuesta oficial y la propuesta editorial...", op. cit.

${ }^{16}$ Miguez, E.: "Reflexiones sobre la enseñanza de la Historia y el uso de fuentes en la escuela media en Argentina”, en Propuesta Educativa, No 7, octubre de 1992, pág. 16.

${ }^{17}$ Ossana Edgardo: op. cit.

${ }^{18}$ Adoptamos la definición que utiliza Hilda Lanza, según la cual se denomina propuesta editorial al conjunto de la producción elaborada por las diferentes editoriales para la propuesta oficial de referencia, supone un trabajo de selección y organización de contenidos al tiempo que la presentación de un determinado discurso, es decir, una reformulación. Lanza, H: "La propuesta oficial...", op. cit., pág. 50.

${ }^{19}$ Lanza, H.: “La propuesta oficial...”, op. cit, pág. 77.

${ }^{20}$ Miguez, E.: op . cit.

${ }^{21}$ Romero, L. A.: "Proyecto visión...”, op. cit.; De Privitellio, L.: "Los otros en la historia escolar. Las 'naciones extranjeras' en los manuales de Historia Argentina entre 1956 y 1989 ”, en Entrepasados No $15,1998$.

${ }^{22}$ De Privitellio, L.: op. cit., pág. 132 y 133. La yuxtaposición es en sí misma una mejora que no cabe despreciar. Los aspectos económicos y sociales se ponen a disposición del docente. No están integrados con los demás contenidos pero pueden ser trabajados.

${ }^{23}$ Frigerio, G. (comp.): Curriculum presente, ciencia ausente. Normas, teorias y criticas, Buenos Aires, Miño y Dávila, 1991, T. I. En este particular, la autora retoma a Chevallard, Las transposition didactique, París, Ed. La pensée sauvage, 1985.

${ }^{24}$ Según Ausubel un aprendizaje es significativo cuando puede ser relacionado con los conocimientos previos del sujeto de un modo sustantivo. Los contenidos por su parte, poseen un potencial de significatividad, es decir, pueden o no ser aprendidos de un modo significativo. Como se ve, el concepto refiere al nivel individual de la problemática educativa. Ver Ausubel. D.: Psicología Educativa. Un punto de vista cognoscitivo, México, Trillas, 1976.

${ }^{25}$ Vezub Lea: "La selección de contenidos curriculares: los criterios de significatividad y relevancia en el conocimiento escolar. Apuntes para la selección de los contenidos de historia”, en Entrepasados, $\mathrm{N}^{\circ}$ 7, 1994. Ver sobre todo el apartado "Algunos principios para seleccionar contenidos de historia", Pág. 161-165. 
${ }^{26}$ König, H. J.: "Los factores del desarrollo económico y social en Argentina y su presentación en los libros de texto", en Propuesta Educativa, No 7, 1992; Sábato, H.: "Del sin-sentido a la interpretación: notas sobre la presentación de la Historia económica en los textos escolares”, en Propuesta Educativa, No 7, 1992.

${ }^{27}$ Sábato, H.: op. cit., pág. 11-13. No se nos escapa el intenso debate que existe en torno de la posibilidad misma de que los alumnos puedan aprehender una diversidad de interpretaciones. De todos modos, creemos que puede ofrecerse un discurso menos neutro y evitar el adoctrinamiento respecto de la historia. Sobre problemas de visión controvertida y perspectiva múltiple ver Riekenberg, M.: "El trabajo con fuentes y la enseñanza de la Historia”, en Propuesta Educativa No 8, 1993.

${ }^{28}$ König, H. J.: op. cit., pág. 8.

${ }^{29}$ Jáuregui, A. y otros: Historia 3, Buenos Aires, Santillana, 1990.

${ }^{30}$ Sobre las transformaciones de la historiografía contemporánea puede consultarse: Stone, L.: El pasado y el presente, México, FCE, 1986; Chartier, R.: El mundo como representación. Historia cultural: entre práctica y representación, Barcelona, Gedisa, 1992; y Noiriel, G.: Sobre la crisis de la historia, Valencia, Frónesis, 1997.

${ }^{31}$ Véase al respecto: Palti, E.: Giro lingüistico e historia intelectual, Universidad Nacional de Quilmes, Buenos Aires, 1998.

${ }^{32}$ Para el análisis del caso argentino puede consultarse Romero, L. A.: "La historiografía argentina en la democracia: los problemas de la construcción de un campo profesional”, en Entrepasados $\mathrm{N}^{\circ} 10$, 1996.

${ }^{33}$ Romero, L. A.: Ibidem.

${ }^{34}$ Romero, L. A. (dir.): "Proyecto Visión argentino-chilena en el sistema educativo (VACHESE). Seminario de difusión y discusión de resultados. Documento de Trabajo”, Buenos Aires, Facultad de Filosofía y Letras, 1998, pág 7.

${ }^{35}$ Acerca del debate sobre libros de texto y enseñanza de la historia, ver Lanza, H.: "La propuesta oficial y la propuesta editorial para la enseñanza de la historia en la escuela media”, en Lanza, H. y Finocchio, S.: Curriculum presente ciencia ausente. La enseñanza de la Historia en la Argentina de hoy, Tomo III, Buenos Aires, Miño y Dávila, 1993.

${ }^{36}$ Braslavsky, C.: "La didáctica de la historia en dos continentes" en Propuesta Educativa No 2, 1990.

${ }^{37}$ Grinberg, S.: “Texto escolar y mercado editorial en contextos de transformación educativa”. En Propuesta Educativa No 17, 1997. 
${ }^{38}$ Como sostiene Miguez, la presencia de fuentes no es una novedad, pero en cada una de las etapas que él define en la evolución de los libros de texto, la fuente tiene una función y relevancia específicas. Ver Miguez, E.: "Reflexiones sobre la enseñanza de la Historia y el uso de fuentes en la escuela media en Argentina”, en Propuesta Educativa No 7, 1992.

${ }^{39}$ Muchas veces se ha criticado el uso de esta multiplicidad de lenguajes por ser responsable de una excesiva fragmentación de los contenidos de la que resulta, en términos de Landi, una suerte de videoclip. Sin embargo, el estilo videoclip puede tener aspectos positivos. Por ejemplo, siguiendo la teoría de Gardner, la diversidad de códigos en que aparece un mismo contenido actúa como un menú, dentro del cual cada estudiante privilegiará el más adecuado para sus condiciones.

${ }^{40}$ Dobaño Fernandez, P.; Lewkowicz, M.; Mussi, R. y Rodriguez, M: "Economía y Revolución en el Río de la Plata: las imágenes creadas por los libros de texto escolares rioplatenses de los '90”, en Actas de las Segundas Jornadas de Historia Económica, Montevideo, AUDHE1999.

${ }^{41}$ Se consultaron de la Editorial Monteverde: El ciclo de las revoluciones. Siglos XVIII y XIX, Colección Pasado-Presente, segundo año, T. II. Autores: Abadie S., Galiana M. A., Nuñez O., Sandrín M., Siniscalco C.; de Kapelusz, Tiempo 2, segunda parte. Autores: Traversoni A., Mazzara S., Arocena M. y de Santillana, Historia 2, segundo año.

${ }^{42}$ Las notas al Cuadro 1 contienen una aclaración sobre los supuestos de los que partimos, y sobre la metodología de cálculo empleada.

${ }^{43}$ De nuestro trabajo comparativo citado, se extrae que los textos uruguayos son los de menor densidad, pues deberían tratar entre 9 y 15 años de historia cada 10 páginas.

${ }^{44}$ Véase la nota (d) del cuadro 2. En los textos uruguayos, el tema de las revoluciones ocupa un promedio de 50 páginas.

${ }^{45}$ Un análisis crítico de los Contenidos Básicos Comunes puede consultarse en Alonso, M. E.:

“Ciencias Sociales sin proceso histórico? Análisis crítico de los nuevos contenidos básicos comunes de ciencias sociales para la educación general”, en Entrepasados, № 8, 1996, pp.147-161. La autora sostiene, entre otras cosas, que la propuesta oficial carece de una lógica disciplinar organizadora, lo que genera una contradicción entre los propósitos que fundamentan la propuesta y los listados de contenidos temáticos que terminan convirtiéndose en una enumeración de temas semejantes a los programas tradicionales.

${ }^{46}$ El sobredimensionamiento relativo de la historia política de los diez años posteriores a la Revolución de Mayo no es una novedad en los textos argentinos. F. Devoto, en su trabajo de 1991, ha encontrado como una de sus características más tradicionales un interés excluyente por el período heroico 
y fundacional de las guerras de independencia. Véase F. Devoto, op. cit. En este punto la propuesta de Oxford es heredera de dicha tradición. Los títulos de algunos apartados en el capítulo dedicado a la revolución dan una idea clara de las características del texto: "Mayo-diciembre 1810: la Primera Junta o Junta Provisional Gubernativa”; “Tiempos difíciles para la Primera Junta”; "Diciembre 1810 - septiembre 1811: la Junta Grande”; “Septiembre 1811 - octubre 1812: el Primer Triunvirato”; Octubre 1812 - enero 1814: el Segundo Triunvirato"; etc.

${ }^{47}$ En nuestro estudio comparativo citado, pudimos observar que los textos uruguayos ofrecen una imagen inversa: tratan detalladamente la historia de las Provincias Unidas del Río de la Plata y prácticamente ignoran la de Brasil.

${ }^{48}$ León, A.: Prensa y educación. Un enfoque cognitivo. Aique, 1996. 